\title{
Relationship of Striatal Dopamine Synthesis Capacity to Age and Cognition
}

\author{
Meredith N. Braskie, ${ }^{1,2}$ Claire E. Wilcox, ${ }^{1,3}$ Susan M. Landau, ${ }^{1,2}$ James P. 0'Neil, ${ }^{2}$ Suzanne L. Baker, ${ }^{2}$ \\ Cindee M. Madison, ${ }^{1}$ Jennifer T. Kluth, ${ }^{1,2}$ and William J. Jagust ${ }^{1,2}$ \\ ${ }^{1}$ Helen Wills Neuroscience Institute, University of California, Berkeley, Berkeley, California 94720-3192, 2Department of Functional Imaging, Lawrence \\ Berkeley National Laboratory, Berkeley, California 94720, and ${ }^{3}$ Department of Psychiatry, University of California, San Francisco, San Francisco, California \\ 94143
}

Past research has demonstrated that performance on frontal lobe-dependent tasks is associated with dopamine system integrity and that various dopamine system deficits occur with aging. The positron emission tomography (PET) radiotracer 6 - $\left[{ }^{18} \mathrm{~F}\right] \mathrm{fluoro}-\mathrm{L}-m$-tyrosine (FMT) is a substrate of the dopamine-synthesizing enzyme, aromatic amino acid decarboxylase (AADC). Studies using 6- $\left[{ }^{18} \mathrm{~F}\right] \mathrm{fluorodopa}$ (FDOPA) (another AADC substrate) to measure how striatal PET signal and age relate have had inconsistent outcomes. The varying results occur in part from tracer processing that renders FDOPA signal subject to aspects of postrelease metabolism, which may themselves change with aging. In contrast, FMT remains a purer measure of AADC function. We used partial volume-corrected FMT PET scans to measure age-related striatal dopamine synthesis capacity in 21 older (mean, 66.9) and 16 younger (mean, 22.8) healthy adults. We also investigated how striatal FMT signal related to a cognitive measure of frontal lobe function. Older adults showed significantly greater striatal FMT signal than younger adults. Within the older group, FMT signal in dorsal caudate (DCA) and dorsal putamen was greater with age, suggesting compensation for deficits elsewhere in the dopamine system. In younger adults, FMT signal in DCA was lower with age, likely related to ongoing developmental processes. Younger adults who performed worse on tests of frontal lobe function showed greater FMT signal in right DCA, independent of age effects. Our data suggest that higher striatal FMT signal represents nonoptimal dopamine processing. They further support a relationship between striatal dopamine processing and frontal lobe cognitive function.

Key words: FMT; PET; normal aging; striatum; cognition; aromatic amino acid decarboxylase; DOPA decarboxylase; caudate; putamen; basal ganglia; prefrontal; upregulation

\section{Introduction}

Performance on frontal lobe-dependent tasks, such as working memory and executive function, relies on the integrity of the striatal dopamine system in normal adults (Bäckman et al., 2000; Erixon-Lindroth et al., 2005; Vernaleken et al., 2007b). Agerelated loss of cerebral dopamine system function has been demonstrated in humans and nonhuman primates (Severson et al., 1982; Seeman et al., 1987; Rinne et al., 1990, 1998; Cordes et al., 1994; Kish et al., 1995; Wang et al., 1998; Kaasinen et al., 2000; van Dyck et al., 2002; Collier et al., 2007). Likewise, a decline in frontal lobe-dependent cognitive function is well established with aging (Cohen et al., 1987; De Luca et al., 2003; Gazzaley et al., 2005). Characterizing the relationship between dopamine and frontal lobe function across the adult lifespan is crucial to understanding cognitive aging.

To explore the association between dopamine and frontal lobe-dependent cognitive function with age, we studied older and younger adults using positron emission tomography (PET)

\footnotetext{
Received Aug. 6, 2008; revised Sept. 25, 2008; accepted Nov. 13, 2008. This work was supported by National Institute on Aging Grant AG027984.

Correspondence should be addressed to Dr. Meredith N. Braskie, Helen Wills Neuroscience Institute, 132 Barker Hall, MC\#3190, Berkeley, CA 94720-3192. E-mail: mbraskie@berkeley.edu. D01:10.1523/JNEUROSCI.3729-08.2008

Copyright $\odot 2008$ Society for Neuroscience ～0270-6474/08/2814320-09\$15.00/0
}

scanning using the radiotracer $6-\left[{ }^{18} \mathrm{~F}\right]$ fluoro-L- $m$-tyrosine (FMT). FMT is a substrate of aromatic amino acid decarboxylase (AADC), which converts levodopa (L-DOPA) to dopamine. Thus, FMT signal represents dopamine synthesis capacity given sufficient substrate.

To date, most PET studies of presynaptic dopamine synthesis have used 6- $\left[{ }^{18} \mathrm{~F}\right]$ fluorodopa (FDOPA), which, like FMT, is a substrate of AADC. Results of studies using FDOPA to measure age-related changes in dopamine synthesis have been inconsistent; some have found decreases in striatal FDOPA signal with age (Martin et al., 1989; Bhatt et al., 1991; Cordes et al., 1994) and some have found no age effect (Sawle et al., 1990; Eidelberg et al., 1993; Ishikawa et al., 1996b). One PET study of nonhuman primates found that FDOPA signal decreased with age, whereas FMT signal increased with age in the same animals (DeJesus et al., 2001). The authors suggested that the disparate results related to differences in what the two tracers measure. Because decarboxylated FDOPA is taken into vesicles and may be released and metabolized further, its signal, particularly at longer scan times, is influenced by both vesicular uptake and postrelease processing (Sossi et al., 2002). In contrast, metabolized FMT in the form of 6 - $\left[{ }^{18} \mathrm{~F}\right]$ fluoro- $m$-tyramine is not a good substrate for vesicular transporters (Endres et al., 1997). Because of this, most FMT signal results from tracer that has been metabolized by AADC 
Table 1. Participant characteristics

\begin{tabular}{|c|c|c|}
\hline & Older & Younger \\
\hline №. of participants & 21 & 16 \\
\hline $\operatorname{Age}^{a, b}$ & $66.9 \pm 7.7$ & $22.8 \pm 2.8$ \\
\hline Males/females & $6 / 15$ & $6 / 10$ \\
\hline Education $^{a, b}$ & $18.4 \pm 2.1$ & $15.8 \pm 1.4$ \\
\hline Mini-Mental State Exam ${ }^{a}$ & $29.3 \pm 1.0$ & $29.4 \pm 0.8$ \\
\hline Listening Span test (total recalled) ${ }^{a, b}$ & $50.7 \pm 9.1$ & $60.2 \pm 9.0$ \\
\hline Digit Span Backward test (total) ${ }^{a}$ & $9.0 \pm 2.8$ & $8.4 \pm 3.0$ \\
\hline 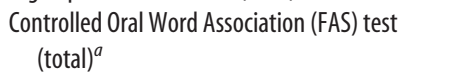 & $47.4 \pm 10.4$ & $49.1 \pm 10.2$ \\
\hline Category Fluency test (total) $)^{a}$ & $37.7 \pm 7.6$ & $39.9 \pm 8.6$ \\
\hline $\begin{array}{l}\text { Stroop C Interference test (no. correct in } 1 \\
\min )^{a, b}\end{array}$ & $50.4 \pm 12.1$ & $64.1 \pm 12.8$ \\
\hline $\begin{array}{l}\text { Wisconsin Card Sort test (\% perseverative } \\
\text { errors) })^{a, c}\end{array}$ & $11.1 \pm 7.9$ & $11.6 \pm 5.7$ \\
\hline Trail Making test (Trails B-A) $(s)^{a, d}$ & $39.6 \pm 38.9$ & $25.7 \pm 13.1$ \\
\hline Composite frontal lobe function score ${ }^{a, e, f}$ & $-0.2 \pm 0.7$ & $0.3 \pm 0.7$ \\
\hline Average FMT signal in bilateral DCA & $0.022 \pm 0.003$ & $0.019 \pm 0.002$ \\
\hline Bilateral DCA volume $\left(\mathrm{mm}^{3}\right)$ & $3893 \pm 698$ & $4807 \pm 921^{g}$ \\
\hline Bilateral DCA volume as \% of intracranial volume & $0.31 \pm 0.04 \%$ & $0.36 \pm 0.07 \%^{g}$ \\
\hline $\begin{array}{l}\text { DCA volume asymmetry (right-left) as \% of } \\
\text { intracranial volume }\end{array}$ & $0.016 \pm 0.014 \%$ & $0.007 \pm 0.008 \%^{h}$ \\
\hline
\end{tabular}

${ }^{a}$ Demographic features are listed as mean \pm SD.

${ }^{b}$ Significant difference between age groups ( $p<0.05$ ) as determined using a two-tailed Mann-Whitney test. 'Score for one younger adult was unavailable.

${ }^{d}$ Scores for two older adults were unavailable.

eSee text for calculation.

'Significant difference between age groups ( $p<0.05$ ) as determined using a two-tailed unpaired $t$ test. ${ }^{9}$ Significant difference between age groups ( $p<0.05$ ), but no significant correlation with FMT signal in bilateral DCA.

${ }^{h}$ Trend toward significant difference between age groups ( $p=0.06$ ), but no significant correlation with DCA FMT asymmetry.

and monoamine oxidase-A (MAO-A), and trapped in axon terminals as $6-\left[{ }^{18} \mathrm{~F}\right]$ fluoro- $m$-hydroxyphenylacetic acid without being released or further processed (Jordan et al., 1997). FMT signal therefore more fully represents the extent of AADC activity (DeJesus et al., 2001). Several past studies have demonstrated age-related changes in enzymes that affect postrelease dopamine processing (Fowler et al., 1980; Saura et al., 1997; Rinne et al., 1998; Harada et al., 2002; van Dyck et al., 2002), potentially affecting the results of FDOPA studies. The in vivo relationship between AADC function alone and age has yet to be characterized in humans.

\section{Materials and Methods}

Subjects. Included in the study were 21 older (57-85; mean, 66.9) and 16 younger (20-30; mean, 22.8) cognitively intact adults (Table 1). Subjects were recruited via newspaper ads, flyers, and online postings. We excluded volunteers who were current smokers, hypertensive, or taking medications that could affect cognition or FMT signal. We also excluded all who were unable to undergo magnetic resonance imaging (MRI) or PET scanning for safety reasons or who had a history of neurological or psychological disorders, major systemic disease, drug or alcohol abuse, or serious head injury. Each subject underwent a full neuropsychiatric battery including tests of executive function, working memory, language, episodic verbal and spatial memory, motor response, and general cognitive function. All had a Mini Mental State Exam (Folstein et al., 1975) score of at least 26. Each scored low average or better for their age on the Wechsler Memory Scale (WMS) Auditory Immediate (Wechsler, 1987) age-adjusted summed score (which includes WMS Logical Memory Immediate score and WMS Verbal Paired Associates Immediate score), and on the Wechsler Adult Intelligence Digit Span (Wechsler, 1981) ageadjusted summed score (which includes Digit Span Forward and Digit Span Backward). No subject had a Geriatric Depression Rating (21 item) score $>10$ (Yesavage et al., 1982). All subjects provided written informed consent before enrolling in the study. Of the 21 older subjects in this study, 20 were reported on previously (Landau et al., 2008). Of the subjects included in the previous study, three were excluded from the current study: one whose PET data were unusable as previously reported, one for whom nearly all of the neuropsychological testing scores were unavailable, and one whose structural MRI scan was not useable for the partial volume correction (PVC) analysis performed here.

Frontal lobe function composite score. Past studies have demonstrated that performance on certain tests thought to depend on frontal lobe function, such as working memory (Mehta et al., 2001; Erixon-Lindroth et al., 2005; Alfimova et al., 2007), verbal fluency (Erixon-Lindroth et al., 2005; Alfimova et al., 2007), and executive function (Vernaleken et al., 2007b; Lane et al., 2008), may be modulated by the dopamine system in healthy adults.

Our neuropsychological battery contained seven tests of frontal lobe function: Listening Span (Daneman and Carpenter, 1980) and Digit Span (Wechsler, 1981), which measure working memory; Controlled Oral Word Association (FAS) (Benton and Hamsher, 1989) and Category Fluency, which measure verbal fluency; and Stroop C Interference (Stroop, 1935), Wisconsin Card Sort Test (WCST) (Heaton, 1993), and Trail Making (Trails B-A) (Reitan, 1958), which measure executive function. Trails B-A scores were not available for two older subjects.

To evaluate the relationship between dopamine synthesis capacity and frontal lobe function, we created a composite cognitive score. Using a composite score derived from several similar test scores both reduces measure variability that might be associated with any one score, and eliminates the need to control for multiple comparisons. To identify tests measuring similar aspects of frontal lobe function, we prepared a covariance matrix containing scores on each test across all subjects. Five tests emerged that were highly correlated with at least three of the other test scores using a Pearson correlation $(p<0.05)$ : Listening Span total recall, FAS, Category Fluency total, Stroop C Interference, and Trails B-A (Table 1). Scores on these tests were normalized as $Z$ scores within the sample. Because a high score on Trails B-A represented worse cognition, whereas a high score on the other four tests represented better cognition, the signs on the $Z$ scores for Trails B-A were reversed before the five scores were averaged to create a composite cognitive score. The composite cognitive score was significantly correlated with each of the five established tests of frontal lobe function from which it was derived $\left(R^{2}\right.$ values ranged from 0.54 to 0.64 ), suggesting that it was a valid measure of frontal lobe-dependent cognitive function. However, although these tests are all thought to measure frontal lobe cognitive function, it is important to note that the tasks are complex and also require abilities such as sensory and motor function that may rely on brain regions other than those thought to subserve the frontal lobe-dependent cognitive function we are trying to measure. Furthermore, the timescale of PET measurements (minutes to hours) is very different from the second to millisecond timescales involved in these cognitive processes.

PET data acquisition. FMT was synthesized at the Lawrence Berkeley National Laboratory as described previously (VanBrocklin et al., 2004). FMT is a well established PET tracer that has been used extensively to study animal models of aging (DeJesus et al., 2001; Eberling et al., 2002) and cognitive function (Cools et al., 2008; Landau et al., 2008), and to measure the effects of gene therapy related to AADC function (Eberling et al., 2008). Details on enzyme specificity, kinetics, and metabolism have been described previously (Srinivasan and Awapara, 1978; DeJesus et al., 1997; Jordan et al., 1997). Radiochemical synthesis for this study produced specific activities of $\sim 1000-2000 \mathrm{mCi} / \mathrm{mmol}$; thus, a typical injection of $3 \mathrm{mCi}$ for a PET imaging experiment would result in a mass dose of the compound of $\sim 3 \mu \mathrm{mol}$, which is unlikely to be pharmacologically active.

Subjects underwent PET scanning on a Siemens ECAT EXACT HR PET scanner in three-dimensional acquisition mode with retractable septae. Forty-seven parallel slices ( $4 \mathrm{~mm}$ thick; $3.6 \mathrm{~mm}$ in-plane voxel size) were acquired.

Subjects ingested $2.5 \mathrm{mg} / \mathrm{kg}$ carbidopa $\sim 60 \mathrm{~min}$ before FMT injection. They were positioned on the scanner bed with a pillow and padding to comfortably restrict head motion. After a 10 min transmission scan obtained for attenuation correction, $\sim 2.5-3.0 \mathrm{mCi}$ of FMT were injected as 
a bolus into an antecubital vein and a dynamic acquisition sequence in three-dimensional mode was obtained: $4 \times 1 \mathrm{~min}, 3 \times 2 \mathrm{~min}, 3 \times 3 \mathrm{~min}$, and $14 \times 5 \mathrm{~min}$ for a total of $89 \mathrm{~min}$ of scan time.

We reconstructed data using an OSEM (ordered subset expectation maximization) algorithm with weighted attenuation, an image size of $256 \times 256$, and six iterations with 16 subsets. A Gaussian filter with $6 \mathrm{~mm}$ full width at half-maximum was applied, with a scatter correction. Images were evaluated for subject motion and adequacy of statistical counts.

MRI scanning. Within 6 months of each PET scan, an MRI scan was obtained using a Varian Unity/Inova whole-body $4.0 \mathrm{~T}$ scanner with a TEM send-and-receive head coil (MR Instruments). MPFLASH (magnetization-prepared fast low angle shot) T1-weighted volumetric scans were acquired for each subject (repetition time, 9 ms; echo time, 4.8 ms; field of view, $22.4 \times 22.4 \times 19.8 \mathrm{~cm}$; matrix size, $256 \times 256 \times 128$; resolution, $0.875 \times 0.875 \times 1.54 \mathrm{~mm}$ ) to be used for region of interest (ROI) demarcation and brain matter masking for PVC of the PET data.

$M R I$ analysis. Bias was removed from each MRI scan using the "FSL Automatic Segmentation Tool” (FAST) from version 3.3 of Oxford Centre for Functional MRI of the Brain "(FMRIB) Software Library" (FSL) (Zhang et al., 2001). Nonlinear noise was then reduced using SUSAN ("Smallest Univalue Segment Assimilating Nucleus") of FSL (Smith, 1992). A mask of MRI scan intracranial matter was automatically generated using the BET ("Brain Extraction Tool") of FSL (Smith, 2002). We then used "FSL view" to manually refine individual intracranial masks, which were next applied to the MRI scans to exclude voxels that did not represent brain matter or CSF. FAST was used to segment the skullstripped brains into brain matter versus CSF. A binary mask of the brain matter alone was created for use in the PVC of the PET data. In addition, we calculated the whole brain matter percentage for each subject, defined as the volume of the brain matter mask divided by the intracranial volume.

PET reference region. Cerebellar masks were drawn in MRI native space on the coronal plane. The masks comprised two-thirds of the slices posterior to the last slice in which the superior cerebellar peduncles stretched superiorly. Including only these most posterior slices ensured that FMT signal from the substantia nigra and ventral tegmental area did not contaminate the reference region. The cerebellum was segmented automatically using FAST to exclude large white matter tracts. To determine whether FMT signal in the cerebellum contributed to our results, for each subject we calculated the average raw FMT cerebellar signal during the first, last, and center PET frames that were included in the final analysis. We compared values at each of the three time points across age groups using a two-tailed Mann-Whitney test. The older and younger groups did not have significantly different cerebellar FMT signal (frame 12, $p=$ 0.82 ; frame $18, p=0.61$; frame $24, p=0.30$ ), signifying that choice of reference region did not influence our results.

PET data analysis. To control for between-frame subject motion, we used six parameter (rigid body) realignment algorithms in Statistical Parametric Mapping (SPM2) (Wellcome Department of Cognitive Neurology, University College London, London, UK). Each PET frame was realigned to the summed image of the first 10 frames. We then used SPM2 to realign the individual MRI scans (along with their accompanying cerebellar gray matter masks and their brain matter masks) to their respective summed PET images, which included considerable anatomic detail from early frames. Next, $K_{\mathrm{i}}$ images were generated using a graphical analysis method for irreversible binding (Patlak and Blasberg, 1985). The approach used a simplified reference tissue model (Lammertsma and Hume, 1996), producing a $K_{\mathrm{i}}$ image that was scaled to the volume of distribution in the reference tissue (cerebellum); we used the term $K_{\mathrm{i}}$ for simplicity. Scaled $K_{\mathrm{i}}$ images were created from PET frames corresponding to 24 through $89 \mathrm{~min}$, using the cerebellar gray matter masks as the reference regions.

Partial volume correction. The accuracy of PET tracer measurements depends on the size of the object being measured relative to the effective resolution (point spread function) of the scanner. Apparent isotope concentrations are depressed for smaller items imaged in scanners with lower resolutions (Hoffman et al., 1979), a phenomenon known as partial volume error. These small items include image voxels that are composed partly of brain tissue (where a radiotracer signal is expected), and partly of CSF (where signal is not expected). Because of partial volume errors at brain/nonbrain boundaries, subjects with greater cortical atrophy or larger surface areas bordering on CSF typically demonstrate apparent PET signal attenuation, which may confound radiotracer parameter estimates. Correction for partial volume errors is necessary to render the data comparable (Tanna et al., 1991; Meltzer et al., 1996; Yanase et al., 2005; Park et al., 2006), especially when brain atrophy associated with aging may be present.

Evidence of the need for PVC may be found in several past in vivo studies of striatal dopamine synthesis having conflicting results in humans and nonhuman primates. Some of these studies have found agerelated decreases in striatal PET signal using FDOPA or $\left[{ }^{11} \mathrm{C}\right]$ DOPA as a PET tracer (Martin et al., 1989; Bhatt et al., 1991; Cordes et al., 1994; DeJesus et al., 2001; Harada et al., 2002; Ota et al., 2006), whereas others found no age effect (Sawle et al., 1990; Eidelberg et al., 1993; Ishikawa et al., 1996b). Some of these differences seem to be methodological. One PET study evaluated how differences in ROI size can influence the results of the FDOPA signal-age relationship. Specifically, striatal FDOPA signal declined significantly with age when PET-drawn ROIs that encompassed the full striatum were used. Conversely, when "small ROIs" composed of small circles throughout the center of the striatum were used, there was no significant effect of striatal FDOPA signal with age (Vingerhoets et al., 1994). One possible explanation for these contrasting results is that, using full striatal ROIs, there is a greater likelihood of partial voluming, which occurs in voxels that border on CSF or white matter. Such a partial volume effect would depress apparent PET signal more in atrophied brains, in which border voxels would compose a larger percentage of the ROI. Because brain atrophy is frequently associated with age (Raz et al., 1995), using full ROIs that have not been corrected for partial volume effects may result in an atrophy-related apparent decrease of PET signal with age and also may affect signal related to developmental striatal volume changes in young adults (Sowell et al., 1999; Bennett and Baird, 2006).

The current study used full striatal ROIs. However, unlike most previous studies, our FMT PET images were partial volume corrected to adjust for signal loss related to variable structure size. PVC was performed using a two-compartment model as described previously (Meltzer et al., 1999). Briefly, the regionally defined scanner point spread function specific to reconstructed data from our PET scanner was convolved with the binary brain matter mask. The corrected PET scan was then calculated as the observed PET signal divided by the convolved brain matter mask, which represented the percentage contribution of brain matter to signal in each voxel (Meltzer et al., 1999). All FMT signal values referenced in Results and Discussion are partial volume corrected unless otherwise noted.

Regions of interest. Dorsal caudate (DCA) and dorsal putamen (DPUT) were drawn on the individual MRI scans using "FSL view." All were drawn using guidelines outlined previously (Mawlawi et al., 2001). After individual MRI scans were coregistered to the corresponding PET images, an average intensity value for each ROI was calculated using the partial volume-corrected $K_{\mathrm{i}}$ image. This average intensity value represented the partial volume-corrected $K_{\mathrm{i}}$ for that ROI. The volumes of the ROIs also were calculated using FSL and were compared with FMT signal.

Depending on the extent to which variations in FMT signal within a brain region exist, the value from an ROI drawn on PET [as in some previous FMT studies (Cools et al., 2008; Landau et al., 2008)] and one drawn on MRI may be quite different. Conceptually, a PET-drawn ROI is one whose PET intensity has been visually thresholded such that only the strongest signal for each subject is included, whereas MRI-drawn ROIs are blind to PET intensity. As such, a PET-drawn ROI will tend to be smaller and will measure PET peak intensity. PET peak intensity will contribute to signal from an MRI-drawn ROI, but the extent of PET signal within the anatomical region will also contribute to the signal. If the percentage of a region having high PET signal were to change with age (e.g., a greater or lesser proportion of cells in a region contained detectable levels of enzyme activity), only an ROI drawn on MRI would identify that change. Although both methods are valid, they emphasize different aspects of the PET signal. MRI-drawn ROIs are necessary for unbiased 


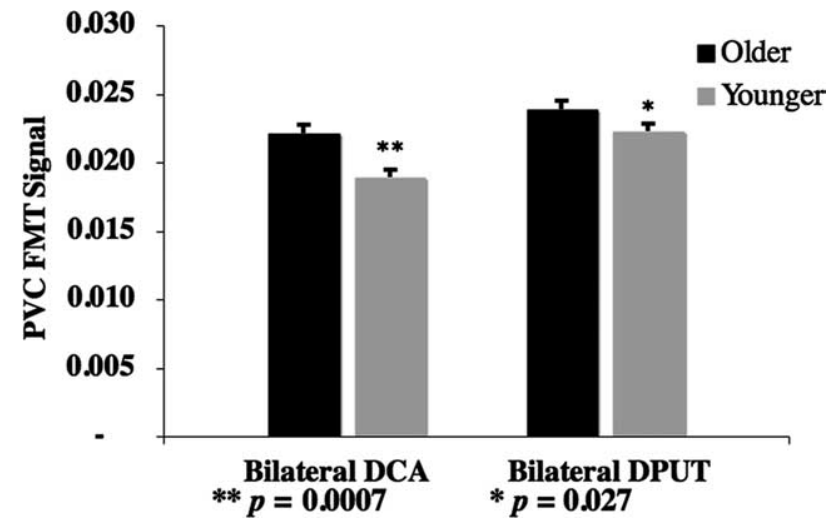

Figure 1. Striatal FMT signal by age. PVC FMT signal in both the bilateral DCA and the bilateral DPUT was significantly greater in older subjects compared with younger subjects (twotailed Mann-Whitney test) (error bars represent SEM).

results when partial volume correction is performed, as in the current study.

Statistics. For comparisons between two groups or two variables whose data were not normally distributed according to a Jarque-Bera test of normality, we used nonparametric tests: the Spearman $\rho$ rank correlation and the normal approximation of the two-tailed Mann-Whitney test. These tests were used for all comparisons unless otherwise noted. For normally distributed data, we used Pearson correlations or two-tailed unpaired $t$ tests. To adjust for age in some comparisons, we used Spearman partial correlations (Schemper 1991). A Spearman partial correlation used here adjusts for age both in the dependent and independent variables in the same way that a Pearson multiple regression would. However, unlike a Pearson multiple regression, this test minimizes the effect of outliers if they exist and is valid even if the data are not normally distributed.

\section{Results}

Relationship between FMT signal and age

FMT values were significantly greater in older subjects than in younger subjects in bilateral DCA $(p=0.0007)$ and, to a lesser extent, in bilateral DPUT ( $p=0.027)$ (Fig. 1).

This relationship was significant in both brain hemispheres (DCA left, $p=0.002$; DCA right, $p=0.001$; DPUT left, $p=0.028$; DPUT right, $p=0.036$ ). Because the relationship between age and $K_{\mathrm{i}}$ in striatum was similar in both hemispheres, for the remainder of this study, we used averaged bilateral $K_{\mathrm{i}}$ values when evaluating the relationship with age.

In addition to between-group striatal FMT signal differences, significant within-group relationships between $K_{\mathrm{i}}$ and age also existed. Specifically, in older adults, $K_{\mathrm{i}}$ in bilateral DCA increased with age (Spearman $\rho=0.69 ; p=0.0005$ ), whereas in younger adults, $K_{\mathrm{i}}$ in bilateral DCA decreased with age $(\rho=-0.76 ; p=$ 0.0007) (Fig. 2A,B). These relationships were significant even when FMT signal was not corrected for partial volume effects $(\rho$ $=0.59 ; p=0.005$ in older adults; $\rho=-0.79 ; p=0.0003$ in younger adults), suggesting that the results were not an artifact of that process.

In older adults, bilateral DPUT $(\rho=0.47 ; p=0.032)$ was significantly greater with age (Fig. 3 ); this effect was reduced to a trend when non-PVC FMT signal was used $(\rho=0.40 ; p=0.076)$. There was no significant relationship between FMT signal in bilateral DPUT and age in the younger group (data not shown).

Relationship between FMT signal and structural volume To determine whether volume or atrophy of the structures may have contributed to the relationships between age and $K_{\mathrm{i}}$ values,
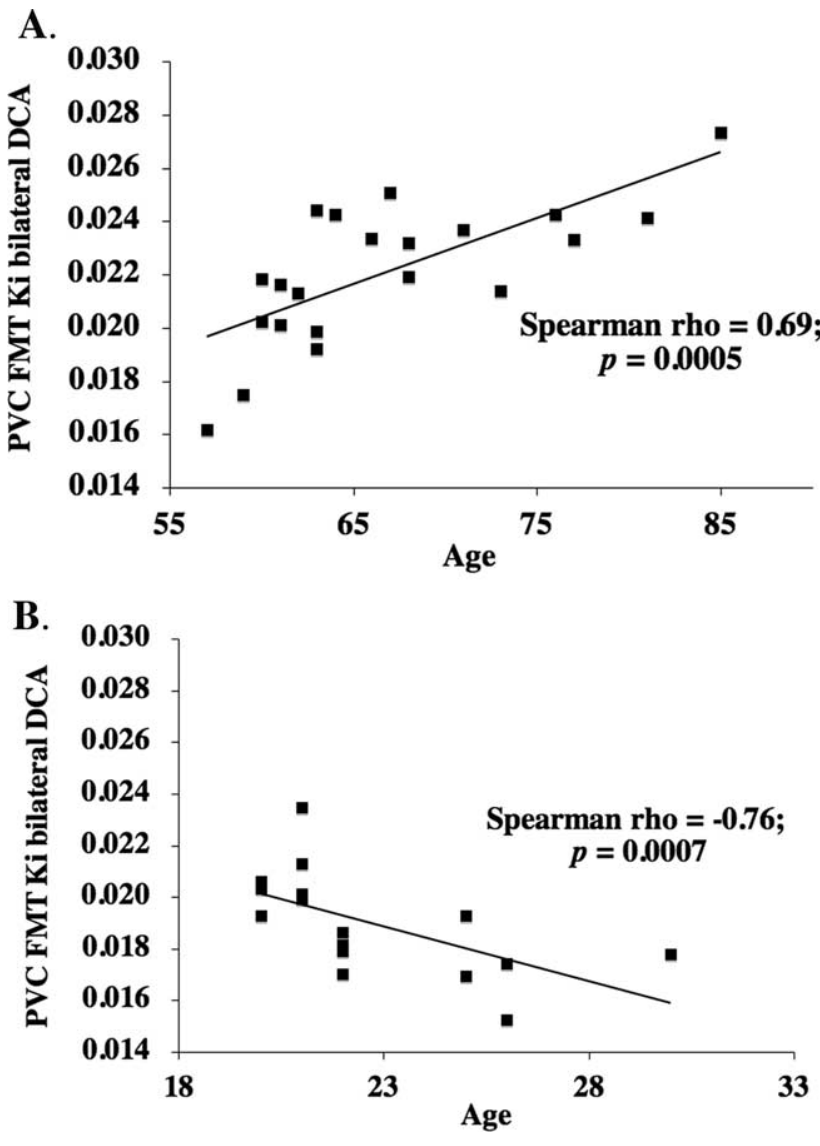

Figure 2. FMT signal in DCA versus age. In the older subjects $(\boldsymbol{A})$, PVC FMT signal in bilateral DCA was higher with increased age, whereas in the younger subjects $(\boldsymbol{B})$, the FMT signal in bilateral DCA was lower with increased age.

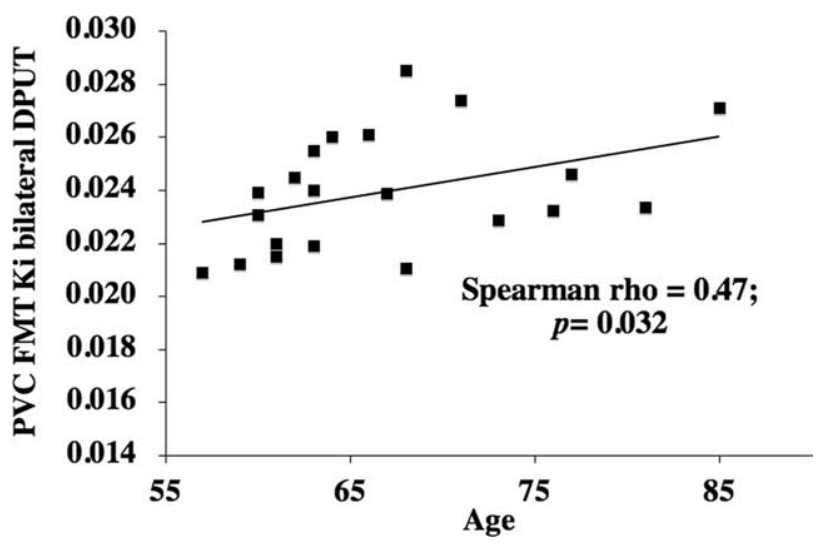

Figure 3. FMT signal in DPUT versus age. In the older subjects, PVC FMT signal in bilateral DPUT was higher with increased age. There was no significant relationship between age and FMT signal in bilateral DPUT in the younger subjects (data not shown).

we examined the relationship between FMT signal and total DCA volume. Total DCA volume was significantly greater in the younger group compared with the older subjects $(p=0.005)$. Total DCA volume as a percentage of intracranial volume, an indication of possible atrophy of that structure, was also larger in younger subjects $(p=0.025)$. However, FMT signal in bilateral DCA was not significantly correlated with either total DCA volume $(\rho=-0.15 ; p=0.36)$, or DCA volume as a percentage of intracranial volume $(\rho=-0.07 ; p=0.67)$, even after controlling for age group using Spearman partial correlation. To provide 
additional evidence that our results were independent of ROI volume, we compared the hemispheric asymmetry in DCA volume with the hemispheric asymmetry in DCA $K_{\mathrm{i}}$ in the same subjects. DCA volume asymmetry was not significantly correlated with $K_{\mathrm{i}}$ asymmetry $(\rho=-0.09 ; p=$ $0.59)$, suggesting that our results were independent of structure size and degree of atrophy (Table 1).

\section{Relationship between FMT signal in DCA and cognition}

In the younger adults, the composite cognitive score was significantly lower in those having higher FMT signal in right

DCA, even after controlling for age using a Spearman partial correlation that included FMT signal and age as independent variables $\left[R^{2}\right.$ (full model $)=0.38 ; p($ full model $)=0.045 ; R^{2}$ (partial contribution of FMT) $=0.38 ; p$ (partial contribution of FMT $)=0.01]$. As expected, there was no significant correlation between FMT signal in the control region (right DPUT) and the composite cognitive score $\left[R^{2}\right.$ (full model) $=0.07 ; p$ (full model $)=0.60 ; R^{2}($ partial contribution of FMT $)=0.07 ; p($ partial contribution of FMT) $=0.32$. To further investigate the significant relationship in DCA, we performed Spearman partial correlations on each of the tests included in the composite cognitive score (Table 2). Although, in the younger adults, FMT signal in right DCA was significantly correlated with that in left DCA $(\rho=0.51 ; p=0.04)$, the relationship between composite cognitive score and age-adjusted FMT signal in left DCA in younger adults was not significant using the Spearman partial correlation $\left[R^{2}(\right.$ full model $)=0.15 ; p($ full model $)=0.36 ; R^{2}$ (partial contribution of FMT) $=0.14 ; p$ (partial contribution of FMT $)=0.16]$. In older adults, the composite cognitive score was not significantly correlated with FMT signal in left DCA $\left[R^{2}\right.$ (full model $)=0.03 ; p($ full model $)=0.75 ; R^{2}$ (partial contribution of FMT $)=0.03 ; p($ partial contribution of FMT $)=0.49$ ] or right DCA $\left[R^{2}(\right.$ full model $)=0.01 ; p($ full model $)=0.88 ; R^{2}($ partial contribution of FMT $)=0.01 ; p($ partial contribution of FMT $)=$ 0.68 ] after adjusting for age.

\section{Relationship between cognition and brain structure}

In the younger group, the composite cognitive score was highest in those subjects having lower (whole brain) brain matter volume as a percentage of intracranial volume $(\rho=-0.55 ; p=0.03)$. Percentage brain matter was not significantly correlated with the composite cognitive score in older subjects.

\section{Discussion}

$K_{\mathrm{i}}$ values in bilateral DCA and DPUT were significantly greater with increased age both between age groups and within our older group alone, suggesting an upregulation of AADC function with age. In contrast, past studies using postmortem brain tissue have reported declines in AADC activity with age (Lloyd and Hornykiewicz, 1972; McGeer and McGeer, 1976), but with variable results in part because of susceptibility of AADC activity to postmortem conditions (Kish et al., 1995). Additionally, enzyme activity measured in brain homogenate ignores modulation from distant brain regions. Other postmortem studies found slightly decreased (Kish et al., 1995) or unchanged (Haycock et al., 2003) AADC protein levels (instead of activity) with age. Kish et al. (1995) surmised that mild decreases in AADC levels, given the larger decreases in dopamine noted previously, indicated increased AADC activity in remaining dopaminergic cell terminals. In vivo techniques such as PET provide a means for testing this hypothesis.

Two studies have examined how FMT uptake in monkey striatum relates to age. Neither showed between-age group differences in striatal $K_{\mathrm{i}}$ values (DeJesus et al., 2001; Eberling et al., 2002). However, when $K_{\mathrm{i}}$ values were correlated with age as a continuous variable in one study, a significant age-related increase in striatal FMT signal emerged, accompanied by an agerelated decrease in striatal FDOPA signal in the same animals (DeJesus et al., 2001).

Because FDOPA, but not FMT, may be taken into vesicles, released, and processed further, it is unsurprising that only FDOPA shows an age-related decrease in striatal signal. At $\sim 90$ min after injection, FDOPA deviates from acting as an irreversible tracer (Sossi et al., 2002), but in most FDOPA studies showing an age-related decline in striatal PET signal, scans lasted 120 min (Martin et al., 1989; Bhatt et al., 1991; Vingerhoets et al., 1994; DeJesus et al., 2001). Therefore, noticeable clearance of the tracer and its metabolites from axon terminals was probably underway by the completion of those scans. Past studies have demonstrated age-related decreases in binding to vesicular transporters (Scherman et al., 1989) and dopamine transporters (DATs) (Ishikawa et al., 1996b; Rinne et al., 1998; Harada et al., 2002; van Dyck et al., 2002; Haycock et al., 2003; Tupala et al., 2003), both of which may be reflected in FDOPA PET scans as lower signal. Likewise, research has shown age-related increases in MAO-B activity (Fowler et al., 1980; Saura et al., 1997), which participates in dopamine (and FDOPA) catabolism. Such catabolism may lead to clearance of the resulting metabolites from the brain (DeJesus et al., 2001; Sossi et al., 2002). Therefore, age-related changes in MAO-B activity could also result in decreased FDOPA signal with age, independent of AADC activity. Although FMT metabolites are substrates for $\mathrm{MAO}-\mathrm{B}$, the resulting product clears very slowly from the brain and actually comprises most of the tracer signal. Changes in MAO-B activity are therefore not expected to affect FMT signal (DeJesus et al., 2005).

Age-related increases in FMT $K_{\mathrm{i}}$ may seem counterintuitive given the striatal dopamine decreases with age seen in some (Adolfsson et al., 1979; Irwin et al., 1994; Cruz-Muros et al., 2007) but not all (Collier et al., 2007) studies. However, AADC is only one feature of the system that results in available dopamine. Greater age-related catabolism of dopamine by MAO-B (Fowler et al., 1980; Saura et al., 1997) may reduce dopamine in the synaptic cleft, whereas lower DAT activity (Ishikawa et al., 1996b; Rinne et al., 1998; Harada et al., 2002; van Dyck et al., 2002; 
Haycock et al., 2003; Tupala et al., 2003) may increase it. Furthermore, in evaluating dopamine synthesis, neither FMT nor FDOPA signal reflects the activity of tyrosine hydroxylase $(\mathrm{TH})$, which converts L-tyrosine to L-DOPA and is the rate-limiting step in dopamine synthesis. L-DOPA is the natural substrate for AADC. Therefore, if L-DOPA levels were to decrease with age, AADC activity also would decline. However, the addition of exogenous AADC substrates (FMT and FDOPA) would mask this effect during scanning. Aging studies of TH levels have been inconclusive, with some (Haycock et al., 2003; Cruz-Muros et al., 2007), but not all (Wolf et al., 1991; Weickert et al., 2007), finding decreases with aging. Because FMT signal measures dopamine synthesis capacity given sufficient substrate, increased FMT uptake could occur in concert with increases or decreases in available dopamine depending on the activity of other dopamine system enzymes.

AADC activity and protein concentrations upregulate in response to declining dopaminergic signaling (Zhu et al., 1992, 1994; Hadjiconstantinou et al., 1993; Ishikawa et al., 1996a; Lee et al., 2000). It is conceivable that (as suggested by our study) such upregulation takes place with aging, reflecting well established age-related decreases in dopamine receptor expression and binding (Severson et al., 1982; Seeman et al., 1987; Suhara et al., 1991; Antonini and Leenders, 1993; Volkow et al., 1996; Ichise et al., 1998; Pohjalainen et al., 1998; Wang et al., 1998; Kaasinen et al., 2000; Weickert et al., 2007), and possible age-related loss of dopaminergic neurons or nerve terminals (Kim et al., 2006; Collier et al., 2007).

Past research supports modulation of striatal dopamine synthesis via available dopamine within both striatum and frontal cortex. Decreased binding of dopamine to $\mathrm{D}_{2}$ autoreceptors within striatum is associated with increased striatal dopamine synthesis and release (Watanabe et al., 1987; Westerink and de Vries, 1989). Likewise, damage to frontal lobe dopaminergic terminals and reductions in frontal lobe dopamine receptor availability enhance dopamine concentrations in striatum by reducing the inhibition of glutamatergic pathways between frontal cortex and striatum (Pycock et al., 1980; Chéramy et al., 1986; Rosin et al., 1992; Roberts et al., 1994). Our data suggest that increased striatal FMT signal indicates compensation for nonoptimal functioning of the dopamine system within the striatum and functionally connected regions.

In contrast to our older subjects, younger adults showed an age-related decrease in DCA FMT signal. Similarly, previous studies comparing adolescents and younger adults to those $>30$ have found associations between youth and elevated levels of striatal and frontal lobe dopamine (Wenk et al., 1989; Collier et al., 2007), higher DAT binding (Zelnik et al., 1986; Mozley et al., 1999), greater dopamine receptor binding and expression (Antonini and Leenders, 1993; Weickert et al., 2007), and lower catechol-O-methyltransferase (COMT) activity in prefrontal cortex (Tunbridge et al., 2007). Working memory, which relies on dopamine signaling (Cai and Arnsten, 1997; Goldman-Rakic et al., 2000), also does not reach peak ability until late adolescence or early adulthood (De Luca et al., 2003; Luna et al., 2004; Clark et al., 2006). Finally, past research has demonstrated that only frontal and striatal structures showed developmental volume reductions between adolescence and early adulthood (Sowell et al., 1999). Together, these studies suggest that, in young adulthood, the still-developing dopamine system has not yet been honed to provide optimal adult dopamine levels. In younger adults, age and FMT values were not significantly correlated in DPUT, whose major connections, unlike those of DCA, are not to the late-developing prefrontal cortex (Alexander et al., 1986).

In normal adults, performance on certain tests of frontal lobedependent cognition may be modulated by the dopamine system endogenously via genotypes (Egan et al., 2001; Mattay et al., 2003; Blasi et al., 2005; Bertolino et al., 2006; Apud et al., 2007; Caldú et al., 2007; Starr et al., 2007; Zhang et al., 2007; Roussos et al., 2008) or exogenously using pharmaceuticals (Roesch-Ely et al., 2005; Gibbs and D'Esposito, 2006; Apud et al., 2007). Past work also has found significant correlations between frontal lobe cognition and FMT, FDOPA, and $\mathrm{D}_{2}$ receptor binding (Bäckman et al., 2000; Vernaleken et al., 2007b; Cools et al., 2008; Landau et al., 2008). In our study, after controlling for age, younger adults showed lower composite cognitive scores with increased FMT signal in right DCA, which is connected to frontal cortex (Alexander et al., 1986). These results support our hypothesis that increased striatal FMT signal represents nonoptimal brain dopamine levels. It is unclear why these results were unilateral, although asymmetries in the dopaminergic system have been noted (Vernaleken et al., 2007a). As expected, the composite cognitive scores were not significantly correlated with FMT signal in the control region (right DPUT), whose major cortical connections are with the supplementary motor area (Alexander et al., 1986). In older adults, DCA FMT signal was not correlated with composite cognitive scores, although past research found a positive correlation between working memory performance and caudate FMT signal using an overlapping subject pool (Landau et al., 2008). This apparent discrepancy arises from methodological differences: specifically, differences in ROI methods and PVC as well as cognitive tests examined (composite cognitive score currently vs Listening Span and Sternberg accuracy scores previously). Although striatal FMT signal was not significantly correlated with the composite cognitive scores in the older adults, this does not preclude dopamine synthesis capacity from contributing to cognitive ability. Cognitive ability, particularly during aging, is influenced by many factors (including those outside the dopamine system) that may obscure the relationship between FMT signal and cognition in this study. Inclusion of more subjects or use of techniques that measure brain activity (such as functional MRI) during a cognitive task may allow us to link cognition to FMT signal in future studies.

Our results suggest that higher FMT signal indicates nonoptimal dopamine system functioning during development and aging. We hypothesize that age-related modulation of striatal FMT reflects dopamine system deficits both in striatum and the connected frontal cortex. Future FMT studies that include evaluation of COMT effects may elucidate interactions between frontal lobe dopamine levels and striatal dopamine synthesis.

\section{References}

Adolfsson R, Gottfries CG, Roos BE, Winblad B (1979) Post-mortem distribution of dopamine and homovanillic acid in human brain, variations related to age, and a review of the literature. J Neural Transm 45:81-105. Alexander GE, DeLong MR, Strick PL (1986) Parallel organization of functionally segregated circuits linking basal ganglia and cortex. Annu Rev Neurosci 9:357-381.

Alfimova MV, Golimbet VE, Gritsenko IK, Lezheiko TV, Abramova LI, Strel'tsova MA, Khlopina IV, Ebstein R (2007) Interaction of dopamine system genes and cognitive functions in patients with schizophrenia and their relatives and in healthy subjects from the general population. Neurosci Behav Physiol 37:643-650.

Antonini A, Leenders KL (1993) Dopamine D2 receptors in normal human brain: effect of age measured by positron emission tomography (PET) and $\left[{ }^{11} \mathrm{C}\right]$-raclopride. Ann N Y Acad Sci 695:81-85.

Apud JA, Mattay V, Chen J, Kolachana BS, Callicott JH, Rasetti R, Alce G, 
Iudicello JE, Akbar N, Egan MF, Goldberg TE, Weinberger DR (2007) Tolcapone improves cognition and cortical information processing in normal human subjects. Neuropsychopharmacology 32:1011-1020.

Bäckman L, Ginovart N, Dixon RA, Wahlin TB, Wahlin A, Halldin C, Farde L (2000) Age-related cognitive deficits mediated by changes in the striatal dopamine system. Am J Psychiatry 157:635-637.

Bennett CM, Baird AA (2006) Anatomical changes in the emerging adult brain: a voxel-based morphometry study. Hum Brain Mapp 27:766-777.

Benton AL, Hamsher KD (1989) Multilingual aphasia examination. Iowa City, IA: AJA Associates.

Bertolino A, Rubino V, Sambataro F, Blasi G, Latorre V, Fazio L, Caforio G, Petruzzella V, Kolachana B, Hariri A, Meyer-Lindenberg A, Nardini M, Weinberger DR, Scarabino T (2006) Prefrontal-hippocampal coupling during memory processing is modulated by COMT val158met genotype. Biol Psychiatry 60:1250-1258.

Bhatt MH, Snow BJ, Martin WR, Pate BD, Ruth TJ, Calne DB (1991) Positron emission tomography suggests that the rate of progression of idiopathic parkinsonism is slow. Ann Neurol 29:673-677.

Blasi G, Mattay VS, Bertolino A, Elvevåg B, Callicott JH, Das S, Kolachana BS, Egan MF, Goldberg TE, Weinberger DR (2005) Effect of catechol-Omethyltransferase val158met genotype on attentional control. J Neurosci 25:5038-5045.

Cai JX, Arnsten AF (1997) Dose-dependent effects of the dopamine D1 receptor agonists A77636 or SKF81297 on spatial working memory in aged monkeys. J Pharmacol Exp Ther 283:183-189.

Caldú X, Vendrell P, Bartrés-Faz D, Clemente I, Bargalló N, Jurado MA, Serra-Grabulosa JM, Junqué C (2007) Impact of the COMT Val108/158 Met and DAT genotypes on prefrontal function in healthy subjects. Neuroimage 37:1437-1444.

Chéramy A, Romo R, Godeheu G, Baruch P, Glowinski J (1986) In vivo presynaptic control of dopamine release in the cat caudate nucleus-II. Facilitatory or inhibitory influence of L-glutamate. Neuroscience 19:1081-1090.

Clark CR, Paul RH, Williams LM, Arns M, Fallahpour K, Handmer C, Gordon E (2006) Standardized assessment of cognitive functioning during development and aging using an automated touchscreen battery. Arch Clin Neuropsychol 21:449-467.

Cohen RL, Sandler SP, Schroeder K (1987) Aging and memory for words and action events: effects of item repetition and list length. Psychol Aging 2:280-285.

Collier TJ, Lipton J, Daley BF, Palfi S, Chu Y, Sortwell C, Bakay RA, Sladek JR Jr, Kordower JH (2007) Aging-related changes in the nigrostriatal dopamine system and the response to MPTP in nonhuman primates: diminished compensatory mechanisms as a prelude to parkinsonism. Neurobiol Dis 26:56-65.

Cools R, Gibbs SE, Miyakawa A, Jagust W, D’Esposito M (2008) Working memory capacity predicts dopamine synthesis capacity in the human striatum. J Neurosci 28:1208-1212.

Cordes M, Snow BJ, Cooper S, Schulzer M, Pate BD, Ruth TJ, Calne DB (1994) Age-dependent decline of nigrostriatal dopaminergic function: a positron emission tomographic study of grandparents and their grandchildren. Ann Neurol 36:667-670.

Cruz-Muros I, Afonso-Oramas D, Abreu P, Barroso-Chinea P, Rodríguez M, González MC, Hernández TG (2007) Aging of the rat mesostriatal system: differences between the nigrostriatal and the mesolimbic compartments. Exp Neurol 204:147-161.

Daneman M, Carpenter PA (1980) Individual differences in working memory and reading. J Verbal Learn Verbal Behav 19:450-466.

DeJesus OT, Endres CJ, Shelton SE, Nickles RJ, Holden JE (1997) Evaluation of fluorinated $m$-tyrosine analogs as PET imaging agents of dopamine nerve terminals: comparison with 6-fluoroDOPA. J Nucl Med 38:630-636.

DeJesus OT, Endres CJ, Shelton SE, Nickles RJ, Holden JE (2001) Noninvasive assessment of aromatic L-amino acid decarboxylase activity in aging rhesus monkey brain in vivo. Synapse 39:58-63.

DeJesus OT, Flores LG, Roberts AD, Dick DW, Bartlett RM, Murali D, Nickles RJ (2005) Aromatic L-amino acid decarboxylase (AAAD) activity in rhesus macaque striatum after MAO-B inhibition by Ro 16-6491. Synapse 56:54-56.

De Luca CR, Wood SJ, Anderson V, Buchanan JA, Proffitt TM, Mahony K, Pantelis C (2003) Normative data from the CANTAB. I: Development of executive function over the lifespan. J Clin Exp Neuropsychol 25:242-254.

Eberling JL, Roberts JA, Taylor SE, VanBrocklin HF, O’Neil JP, Nordahl TE
(2002) No effect of age and estrogen on aromatic L-amino acid decarboxylase activity in rhesus monkey brain. Neurobiol Aging 23:479-483.

Eberling JL, Jagust WJ, Christine CW, Starr P, Larson P, Bankiewicz KS, Aminoff MJ (2008) Neurology 70:1980-1983.

Egan MF, Goldberg TE, Kolachana BS, Callicott JH, Mazzanti CM, Straub RE, Goldman D, Weinberger DR (2001) Effect of COMT Val108/158 Met genotype on frontal lobe function and risk for schizophrenia. Proc Natl Acad Sci U S A 98:6917-6922.

Eidelberg D, Takikawa S, Dhawan V, Chaly T, Robeson W, Dahl R, Margouleff D, Moeller JR, Patlak CS, Fahn S (1993) Striatal ${ }^{18} \mathrm{~F}$-dopa uptake: absence of an aging effect. J Cereb Blood Flow Metab 13:881-888.

Endres CJ, Swaminathan S, DeJesus OT, Sievert M, Ruoho AE, Murali D, Rommelfanger SG, Holden JE (1997) Affinities of dopamine analogs for monoamine granular and plasma membrane transporters: implications for PET dopamine studies. Life Sci 60:2399-2406.

Erixon-Lindroth N, Farde L, Wahlin TB, Sovago J, Halldin C, Bäckman L (2005) The role of the striatal dopamine transporter in cognitive aging. Psychiatry Res 138:1-12.

Folstein MF, Folstein SE, McHugh PR (1975) “Mini-mental state." A practical method for grading the cognitive state of patients for the clinician. J Psychiatr Res 12:189-198.

Fowler CJ, Wiberg A, Oreland L, Marcusson J, Winblad B (1980) The effect of age on the activity and molecular properties of human brain monoamine oxidase. J Neural Transm 49:1-20.

Gazzaley A, Cooney JW, Rissman J, D’Esposito M (2005) Top-down suppression deficit underlies working memory impairment in normal aging. Nat Neurosci 8:1298-1300.

Gibbs SE, D'Esposito M (2006) A functional magnetic resonance imaging study of the effects of pergolide, a dopamine receptor agonist, on component processes of working memory. Neuroscience 139:359-371.

Goldman-Rakic PS, Muly EC 3rd, Williams GV (2000) $D_{1}$ receptors in prefrontal cells and circuits. Brain Res Brain Res Rev 31:295-301.

Hadjiconstantinou M, Wemlinger TA, Sylvia CP, Hubble JP, Neff NH (1993) Aromatic L-amino acid decarboxylase activity of mouse striatum is modulated via dopamine receptors. J Neurochem 60:2175-2180.

Harada N, Nishiyama S, Satoh K, Fukumoto D, Kakiuchi T, Tsukada H (2002) Age-related changes in the striatal dopaminergic system in the living brain: a multiparametric PET study in conscious monkeys. Synapse 45:38-45.

Haycock JW, Becker L, Ang L, Furukawa Y, Hornykiewicz O, Kish SJ (2003) Marked disparity between age-related changes in dopamine and other presynaptic dopaminergic markers in human striatum. J Neurochem 87:574-585.

Heaton R (1993) Wisconsin Card Sorting Test manual: revised and expanded. Odessa, FL: Psychological Assessment Resources.

Hoffman EJ, Huang SC, Phelps ME (1979) Quantitation in positron emission computed tomography: 1. Effect of object size. J Comput Assist Tomogr 3:299-308.

Ichise M, Ballinger JR, Tanaka F, Moscovitch M, St George-Hyslop PH, Raphael D, Freedman M (1998) Age-related changes in D2 receptor binding with iodine-123-iodobenzofuran SPECT. J Nucl Med 39:1511-1518.

Irwin I, DeLanney LE, McNeill T, Chan P, Forno LS, Murphy GM Jr, Di Monte DA, Sandy MS, Langston JW (1994) Aging and the nigrostriatal dopamine system: a non-human primate study. Neurodegeneration 3:251-265.

Ishikawa T, Dhawan V, Chaly T, Margouleff C, Robeson W, Dahl JR, Mandel F, Spetsieris P, Eidelberg D (1996a) Clinical significance of striatal DOPA decarboxylase activity in Parkinson's disease. J Nucl Med 37:216-222.

Ishikawa T, Dhawan V, Kazumata K, Chaly T, Mandel F, Neumeyer J, MargouleffC, Babchyck B, Zanzi I, Eidelberg D (1996b) Comparative nigrostriatal dopaminergic imaging with iodine-123-beta CIT-FP/SPECT and fluorine-18-FDOPA/PET. J Nucl Med 37:1760-1765.

Jordan S, Eberling JL, Bankiewicz KS, Rosenberg D, Coxson PG, VanBrocklin HF, O’Neil JP, Emborg ME, Jagust WJ (1997) 6- $\left[{ }^{18} \mathrm{~F}\right]$ fluoro-L-m-tyrosine: metabolism, positron emission tomography kinetics, and 1-methyl-4-phenyl-1,2,3,6-tetrahydropyridine lesions in primates. Brain Res 750:264-276.

Kaasinen V, Vilkman H, Hietala J, Någren K, Helenius H, Olsson H, Farde L, Rinne J (2000) Age-related dopamine D2/D3 receptor loss in extrastriatal regions of the human brain. Neurobiol Aging 21:683-688.

Kim ST, Choi JH, Kim D, Hwang O (2006) Increases in TH immunoreactivity, neuromelanin and degeneration in the substantia nigra of middle aged mice. Neurosci Lett 396:263-268. 
Kish SJ, Zhong XH, Hornykiewicz O, Haycock JW (1995) Striatal 3,4dihydroxyphenylalanine decarboxylase in aging: disparity between postmortem and positron emission tomography studies? Ann Neurol 38:260-264.

Lammertsma AA, Hume SP (1996) Simplified reference tissue model for PET receptor studies. Neuroimage 4:153-158.

Landau SM, Lal R, O’Neil JP, Baker S, Jagust WJ (2008) Striatal dopamine and working memory. Cereb Cortex. Advance online publication. Retrieved December 2, 2008. doi:10.1093/cercor/bhn095

Lane HY, Liu YC, Huang CL, Hsieh CL, Chang YL, Chang L, Chang YC, Chang WH (2008) Prefrontal executive function and $\mathrm{D}(1), \mathrm{D}(3)$, 5-HT(2A) and 5-HT(6) receptor gene variations in healthy adults. J Psychiatry Neurosci 33:47-53.

Lee CS, Samii A, Sossi V, Ruth TJ, Schulzer M, Holden JE, Wudel J, Pal PK, de la Fuente-Fernandez R, Calne DB, Stoessl AJ (2000) In vivo positron emission tomographic evidence for compensatory changes in presynaptic dopaminergic nerve terminals in Parkinson's disease. Ann Neurol 47:493-503.

Lloyd KG, Hornykiewicz O (1972) Occurrence and distribution of aromatic L-amino acid (L-DOPA) decarboxylase in the human brain. J Neurochem 19:1549-1559.

Luna B, Garver KE, Urban TA, Lazar NA, Sweeney JA (2004) Maturation of cognitive processes from late childhood to adulthood. Child Dev 75:1357-1372.

Martin WR, Palmer MR, Patlak CS, Calne DB (1989) Nigrostriatal function in humans studied with positron emission tomography. Ann Neurol 26:535-542.

Mattay VS, Goldberg TE, Fera F, Hariri AR, Tessitore A, Egan MF, Kolachana B, Callicott JH, Weinberger DR (2003) Catechol O-methyltransferase val158-met genotype and individual variation in the brain response to amphetamine. Proc Natl Acad Sci U S A 100:6186-6191.

Mawlawi O, Martinez D, Slifstein M, Broft A, Chatterjee R, Hwang DR, Huang Y, Simpson N, Ngo K, Van Heertum R, Laruelle M (2001) Imaging human mesolimbic dopamine transmission with positron emission tomography: I. Accuracy and precision of D(2) receptor parameter measurements in ventral striatum. J Cereb Blood Flow Metab 21:1034-1057.

McGeer PL, McGeer EG (1976) Enzymes associated with the metabolism of catecholamines, acetylcholine and gaba in human controls and patients with Parkinson's disease and Huntington's chorea. J Neurochem 26:65-76.

Mehta MA, Swainson R, Ogilvie AD, Sahakian J, Robbins TW (2001) Improved short-term spatial memory but impaired reversal learning following the dopamine $\mathrm{D}(2)$ agonist bromocriptine in human volunteers. Psychopharmacology (Berl) 159:10-20.

Meltzer CC, Zubieta JK, Brandt J, Tune LE, Mayberg HS, Frost JJ (1996) Regional hypometabolism in Alzheimer's disease as measured by positron emission tomography after correction for effects of partial volume averaging. Neurology 47:454-461.

Meltzer CC, Kinahan PE, Greer PJ, Nichols TE, Comtat C, Cantwell MN, Lin MP, Price JC (1999) Comparative evaluation of MR-based partialvolume correction schemes for PET. J Nucl Med 40:2053-2065.

Mozley PD, Acton PD, Barraclough ED, Plössl K, Gur RC, Alavi A, Mathur A, Saffer J, Kung HF (1999) Effects of age on dopamine transporters in healthy humans. J Nucl Med 40:1812-1817.

Ota M, Yasuno F, Ito H, Seki C, Nozaki S, Asada T, Suhara T (2006) Agerelated decline of dopamine synthesis in the living human brain measured by positron emission tomography with $\mathrm{L}-\left[\right.$ beta- $\left.{ }^{11} \mathrm{C}\right]$ DOPA. Life Sci 79:730-736.

Park HJ, Lee JD, Chun JW, Seok JH, Yun M, Oh MK, Kim JJ (2006) Cortical surface-based analysis of ${ }^{18}$ F-FDG PET: measured metabolic abnormalities in schizophrenia are affected by cortical structural abnormalities. Neuroimage 31:1434-1444.

Patlak CS, Blasberg RG (1985) Graphical evaluation of blood-to-brain transfer constants from multiple-time uptake data. Generalizations. J Cereb Blood Flow Metab 5:584-590.

Pohjalainen T, Rinne JO, Någren K, Syvälahti E, Hietala J (1998) Sex differences in the striatal dopamine D2 receptor binding characteristics in vivo. Am J Psychiatry 155:768-773.

Pycock CJ, Kerwin RW, Carter CJ (1980) Effect of lesion of cortical dopamine terminals on subcortical dopamine receptors in rats. Nature 286:74-76.

Raz N, Torres IJ, Acker JD (1995) Age, gender, and hemispheric differences in human striatum: a quantitative review and new data from in vivo MRI morphometry. Neurobiol Learn Mem 63:133-142.

Reitan RM (1958) Validity of the Trailmaking Test as an indicator of organic brain damage. Percept Mot Skills 8:271-276.

Rinne JO, Lönnberg P, Marjamäki P (1990) Age-dependent decline in human brain dopamine D1 and D2 receptors. Brain Res 508:349-352.

Rinne JO, Sahlberg N, Ruottinen H, Någren K, Lehikoinen P (1998) Striatal uptake of the dopamine reuptake ligand $\left[{ }^{11} \mathrm{C}\right]$ beta-CFT is reduced in Alzheimer's disease assessed by positron emission tomography. Neurology 50:152-156.

Roberts AC, De Salvia MA, Wilkinson LS, Collins P, Muir JL, Everitt BJ, Robbins TW (1994) 6-Hydroxydopamine lesions of the prefrontal cortex in monkeys enhance performance on an analog of the Wisconsin Card Sort Test: possible interactions with subcortical dopamine. J Neurosci 14:2531-2544.

Roesch-Ely D, Scheffel H, Weiland S, Schwaninger M, Hundemer HP, Kolter T, Weisbrod M (2005) Differential dopaminergic modulation of executive control in healthy subjects. Psychopharmacology (Berl) 178:420-430.

Rosin DL, Clark WA, Goldstein M, Roth RH, Deutch AY (1992) Effects of 6-hydroxydopamine lesions of the prefrontal cortex on tyrosine hydroxylase activity in mesolimbic and nigrostriatal dopamine systems. Neuroscience 48:831-839.

Roussos P, Giakoumaki SG, Pavlakis S, Bitsios P (2008) Planning, decisionmaking and the COMT rs4818 polymorphism in healthy males. Neuropsychologia 46:757-763.

Saura J, Andrés N, Andrade C, Ojuel J, Eriksson K, Mahy N (1997) Biphasic and region-specific MAO-B response to aging in normal human brain. Neurobiol Aging 18:497-507.

Sawle GV, Colebatch JG, Shah A, Brooks DJ, Marsden CD, Frackowiak RS (1990) Striatal function in normal aging: implications for Parkinson's disease. Ann Neurol 28:799-804.

Schemper M (1991) Non-parametric partial association revisited. Statistician 40:73-76.

Scherman D, Desnos C, Darchen F, Pollak P, Javoy-Agid F, Agid Y (1989) Striatal dopamine deficiency in Parkinson's disease: role of aging. Ann Neurol 26:551-557.

Seeman P, Bzowej NH, Guan HC, Bergeron C, Becker LE, Reynolds GP, Bird ED, Riederer P, Jellinger K, Watanabe S, Tourtellotte WW (1987) Human brain dopamine receptors in children and aging adults. Synapse 1:399-404.

Severson JA, Marcusson J, Winblad B, Finch CE (1982) Age-correlated loss of dopaminergic binding sites in human basal ganglia. J Neurochem 39:1623-1631.

Smith SM (1992) A new class of corner finder. Proceedings of the Third British Machine Vision Conference, Leeds, UK, January.

Smith SM (2002) Fast robust automated brain extraction. Hum Brain Mapp 17:143-155.

Sossi V, de La Fuente-Fernández R, Holden JE, Doudet DJ, McKenzie J, Stoessl AJ, Ruth TJ (2002) Increase in dopamine turnover occurs early in Parkinson's disease: evidence from a new modeling approach to PET ${ }^{18}$ F-fluorodopa data. J Cereb Blood Flow Metab 22:232-239.

Sowell ER, Thompson PM, Holmes CJ, Jernigan TL, Toga AW (1999) In vivo evidence for post-adolescent brain maturation in frontal and striatal regions. Nat Neurosci 2:859-861.

Srinivasan K, Awapara J (1978) Substrate specificity and other properties of DOPA decarboxylase from guinea pig kidneys. Biochem Biophys Acta 526:597-604.

Starr JM, Fox H, Harris SE, Deary IJ, Whalley LJ (2007) COMT genotype and cognitive ability: a longitudinal aging study. Neurosci Lett 421:57-61.

Stroop JR (1935) Studies of interference in serial verbal reactions. J Exp Psychol 18:643-662.

Suhara T, Fukuda H, Inoue O, Itoh T, Suzuki K, Yamasaki T, Tateno Y (1991) Age-related changes in human D1 dopamine receptors measured by positron emission tomography. Psychopharmacology (Berl) 103:41-45.

Tanna NK, Kohn MI, Horwich DN, Jolles PR, Zimmerman RA, Alves WM, Alavi A (1991) Analysis of brain and cerebrospinal fluid volumes with MR imaging: impact on PET data correction for atrophy. Part II. Aging and Alzheimer dementia. Radiology 178:123-130.

Tunbridge EM, Weickert CS, Kleinman JE, Herman MM, Chen J, Kolachana BS, Harrison PJ, Weinberger DR (2007) Catechol-O-methyltransferase enzyme activity and protein expression in human prefrontal cortex across the postnatal lifespan. Cereb Cortex 17:1206-1212. 
Tupala E, Hall H, Bergström K, Mantere T, Räsänen P, Särkioja T, Hiltunen J, Tiihonen J (2003) Different effect of age on dopamine transporters in the dorsal and ventral striatum of controls and alcoholics. Synapse 48:205-211.

VanBrocklin HF, Blagoev M, Hoepping A, O’Neil JP, Klose M, Schubiger PA, Ametamey S (2004) A new precursor for the preparation of 6- $\left[{ }^{18} \mathrm{~F}\right]$ fluoro-L- $m$-tyrosine $\left(\left[{ }^{18} \mathrm{~F}\right] \mathrm{FMT}\right)$ : efficient synthesis and comparison of radiolabeling. Appl Radiat Isot 61:1289-1294.

van Dyck CH, Seibyl JP, Malison RT, Laruelle M, Zoghbi SS, Baldwin RM, Innis RB (2002) Age-related decline in dopamine transporters: analysis of striatal subregions, nonlinear effects, and hemispheric asymmetries. Am J Geriatr Psychiatry 10:36-43.

Vernaleken I, Weibrich C, Siessmeier T, Buchholz HG, Rösch F, Heinz A, Cumming P, Stoeter P, Bartenstein P, Gründer G (2007a) Asymmetry in dopamine $\mathrm{D}(2 / 3)$ receptors of caudate nucleus is lost with age. Neuroimage 34:870-878.

Vernaleken I, Buchholz HG, Kumakura Y, Siessmeier T, Stoeter P, Bartenstein P, Cumming P, Gründer G (2007b) "Prefrontal" cognitive performance of healthy subjects positively correlates with cerebral FDOPA influx: an exploratory $\left[{ }^{18} \mathrm{~F}\right]$-fluoro-L-DOPA-PET investigation. Hum Brain Mapp 28:931-939.

Vingerhoets FJ, Snow BJ, Schulzer M, Morrison S, Ruth TJ, Holden JE, Cooper S, Calne DB (1994) Reproducibility of fluorine-18-6-fluorodopa positron emission tomography in normal human subjects. J Nucl Med 35:18-24.

Volkow ND, Wang GJ, Fowler JS, Logan J, Gatley SJ, MacGregor RR, Schlyer DJ, Hitzemann R, Wolf AP (1996) Measuring age-related changes in dopamine D2 receptors with ${ }^{11} \mathrm{C}$-raclopride and ${ }^{18} \mathrm{~F}-\mathrm{N}$ methylspiroperidol. Psychiatry Res 67:11-16.

Wang Y, Chan GL, Holden JE, Dobko T, Mak E, Schulzer M, Huser JM, Snow BJ, Ruth TJ, Calne DB, Stoessl AJ (1998) Age-dependent decline of dopamine D1 receptors in human brain: a PET study. Synapse 30:56-61.

Watanabe H, Suda H, Sekihara S, Nomura Y (1987) D-1 type of dopamine autoreceptors are not involved in the regulation of dopamine synthesis in the striatum. Jpn J Pharmacol 43:327-330.

Wechsler D (1981) Wechsler Adult Intelligence Scale—revised. San Antonio, TX: The Psychological Corporation.
Wechsler D (1987) Wechsler Memory Scale—revised manual. San Antonio, TX: The Psychological Corporation.

Weickert CS, Webster MJ, Gondipalli P, Rothmond D, Fatula RJ, Herman MM, Kleinman JE, Akil M (2007) Postnatal alterations in dopaminergic markers in the human prefrontal cortex. Neuroscience 144:1109-1119.

Wenk GL, Pierce DJ, Struble RG, Price DL, Cork LC (1989) Age-related changes in multiple neurotransmitter systems in the monkey brain. Neurobiol Aging 10:11-19.

Westerink BH, de Vries JB (1989) On the mechanism of neuroleptic induced increase in striatal dopamine release: brain dialysis provides direct evidence for mediation by autoreceptors localized on nerve terminals. Neurosci Lett 99:197-202.

Wolf ME, LeWitt PA, Bannon MJ, Dragovic LJ, Kapatos G (1991) Effect of aging on tyrosine hydroxylase protein content and the relative number of dopamine nerve terminals in human caudate. J Neurochem 56:1191-1200.

Yanase D, Matsunari I, Yajima K, Chen W, Fujikawa A, Nishimura S, Matsuda H, Yamada M (2005) Brain FDG PET study of normal aging in Japanese: effect of atrophy correction. Eur J Nucl Med Mol Imaging 32:794-805.

Yesavage JA, Brink TL, Rose TL, Lum O, Huang V, Adey M, Leirer VO (1982) Development and validation of a geriatric depression screening scale: a preliminary report. J Psychiatr Res 17:37-49.

Zelnik N, Angel I, Paul SM, Kleinman JE (1986) Decreased density of human striatal dopamine uptake sites with age. Eur J Pharmacol 126:175-176.

Zhang Y, Brady M, Smith S (2001) Segmentation of brain MR images through a hidden Markov random field model and the expectationmaximization algorithm. IEEE Trans Med Imaging 20:45-57.

Zhang Y, Bertolino A, Fazio L, Blasi G, Rampino A, Romano R, Lee ML, Xiao T, Papp A, Wang D, Sadée W (2007) Polymorphisms in human dopamine D2 receptor gene affect gene expression, splicing, and neuronal activity during working memory. Proc Natl Acad Sci U S A 104:20552-20557.

Zhu MY, Juorio AV, Paterson IA, Boulton AA (1992) Regulation of aromatic L-amino acid decarboxylase by dopamine receptors in the rat brain. J Neurochem 58:636-641.

Zhu MY, Juorio AV, Paterson IA, Boulton AA (1994) Regulation of aromatic L-amino acid decarboxylase in rat striatal synaptosomes: effects of dopamine receptor agonists and antagonists. Br J Pharmacol 112:23-30. 